\title{
The CAS50 Exhibition and Collection
}

\author{
Sean Clark \\ Interact Digital Arts Ltd \\ Leicester, UK \\ seanc@interactdigitalarts.uk
}

\begin{abstract}
The Computer Arts Society was established in the UK in 1968 and pioneered the development of digital arts in the UK and worldwide. In this paper I present some background to the formation of the Society and document the exhibition organised to help celebrate $\mathbf{5 0}$ years since the founding of the Society. Suggestions for the on-going development of what is now being referred to as the "CAS50 Collection" are also presented.
\end{abstract}

Computer Arts Society. Computer art. Digital art. Art exhibition.

\section{THE COMPUTER ARTS SOCIETY}

In 1968 the three founder members of the Computer Arts Society - Alan Sutcliffe, George Mallen and John Lansdown - had been involved with computing and its related topics for some time. They knew Jasia Reichardt, the curator the of Cybernetic Serendipity exhibition in 1968 (Reichardt 1968) and had participated in, or advised, on various aspects of the show.

Sutcliffe was involved with the Cybernetic Serendipity exhibition through his collaboration with composer Peter Zinovieff and Electronic Music Studios (EMS). Mallen was working with the English cybernetician Gordon Pask at Systems Research and assisted on the production of the interactive robotic work Colloquy of Mobiles, shown at the exhibition. Although not mentioned in the catalogue credits, Reichardt knew of Lansdown, who from 1963 had used computing techniques in architectural design and planning.

A society dedicated to the computer arts (which was to become the Computer Arts Society) was initiated by Sutcliffe at the International Federation for Information Processing Congress in August 1968 in Edinburgh. Sutcliffe and Zinovieff had won second prize with ZASP, their piece of computercomposed music. Members of the Congress suggested to Sutcliffe that he might like to convene a meeting of people working in a similar field whilst they were all together at the Congress, as most had not had a chance to meet like-minded persons outside their own team before. Sutcliffe collated the names of interested individuals and the group formed out of this, with the first meetings in London held in a room belonging to University College London, in or near Gower Street in September 1968. Subsequent meetings were often held at the offices of Lansdown's architectural practice (he became the Secretary with Sutcliffe the Chairman and Mallen, Treasurer).

The Computer Arts Society was founded with the aim of encouraging the creative use of computers and to allow the exchange of information in this area. It was recognised that this was an area where there had been increasing activity, but with little formal publication of methods and results and little communication between artists in different fields (music, visual, performing arts, and so on). The Society addressed this by publishing PAGE, its own news bulletin.

\section{PAGE}

PAGE was first published in April 1969 (see Figure 1) and was an important vehicle for communicating the Society's activities, particularly in its early years. The bulletin was first edited by autodestructive artist Gustaz Metzger and has since been edited by Alan Sutcliffe, Dominic Boreham, Paul Brown and others.

Between 1969 and 1985 there were 52 issues of PAGE - ranging in size from one-page bulletins to 
full magazines. There was then a hiatus from 1985 until 2004, after which 13 additional issues have since been published. In March 2018 a complete set of scanned copies of PAGE (and related publications) was made available as a collection of free PDFs on the Computer Arts Society archive (Computer Arts Society 2019), with much of the scanning being undertaken by the current CAS Chair, Nick Lambert.

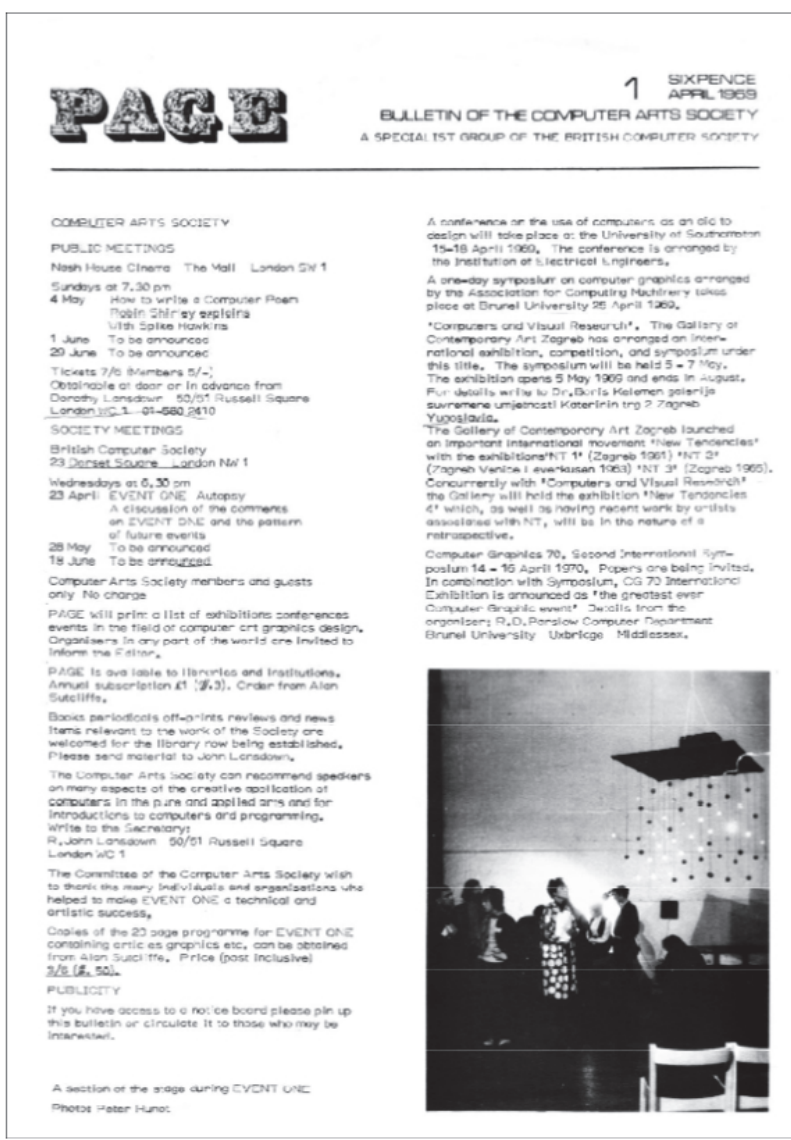

Figure 1: PAGE Issue 1, April 1969.

\section{RECENT ACTIVITIES}

The Computer Arts Society originally ran from 1968 until 1985. In 2002 the CACHe project at the Vasari $\mathrm{Lab}$ in the School of History of Art and Visual Media, Birkbeck, University of London began to digitise and catalogue the image holdings of the Society and related archives. This resulted in the re-establishment of the Computer Arts Society in 2004. The core archive was then acquired by the Victoria and Albert Museum and now forms part of their Computer Art Collections.

Two books, A Computer in the Art Room: The Origins of British Computer Arts 1950-1980 by Catherine Mason (2008) and White Heat Cold Logic: British Computer Art 1960-1980 by Paul Brown, Catherine Mason, Charlie Gere and Nicholas Lambert (2009), have been published that describe in detail the early history of computer art, including the early CAS period.

A follow-up project entitled Computer Art and Technocultures, based jointly at Birkbeck and the Victoria and Albert Museum, ran from December 2009 until April 2010. This project hosted a symposium, Ideas Before Their Time at the British Computer Society on $3^{\text {rd }}$ February 2010 and a twoday conference, Decoding the Digital, at the V\&A on 4th-5th February 2010.

Since re-forming in 2004, the Computer Arts Society has run an extensive speaker programme from its base at the British Computer Society in London, as well as from other London venues and more recently in Leicester.

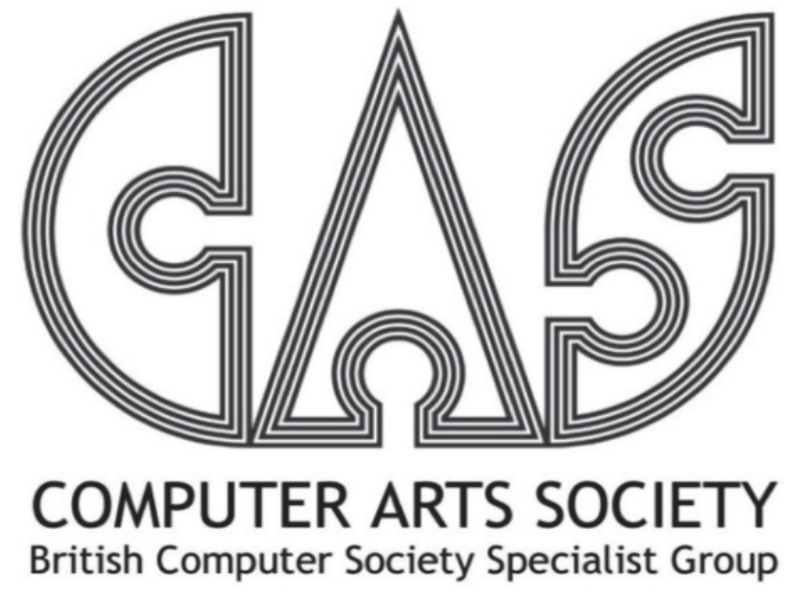

Figure 2: The Computer Arts Society logo.

The Society also runs the annual Electronic Visualisation \& the Arts (EVA) conference in London. Through its status as a Specialist Group of the British Computer Society it is able to regularly support exhibitions and other computer art activities throughout the year.

\section{THE CAS50 EXHIBITION}

The initial idea for a celebratory exhibition focused on the $50^{\text {th }}$ anniversary of the founding of the Computer Arts Society was to look to produce a collection of reprints of pioneering computer artworks. However, it soon became apparent that interest in the exhibition was such that artists were happy to donate originals to the exhibition.

An initial twelve artists were approached - Stephen Bell, Peter Beyls, boredomresearch, Daniel Brown, Paul Brown, Sean Clark, Ernest Edmonds, Sue Gollifer, Desmond Henry, William Latham, Andy Lomas and Stephen Scrivener. All artists immediately agreed to be involved and offered work. 
The curation criteria for artworks were that the artists should have had an association with the Computer Arts Society at some point over the years and that the artists were easily contactable. I also wanted to represent the generative and organic nature of much of the artwork by the artists who have been members of the Computer Arts Society.

While I would argue that the work included is representative of the Computer Arts Society's members, I would also accept that it is something of a personal view. A suggestion to broaden the type of work featured in future exhibitions is presented later.

\subsection{The Leicester Exhibition}

The first exhibition of what had now become the CAS50 Collection, took place at the LCB Lightbox Gallery in Leicester between $21^{\text {st }}$ May and $13^{\text {th }}$ June 2018. With some artists contributing multiple pieces, around 20 artworks were on display.

The opening event on the $23^{\text {rd }}$ May was well attended, with many of the artists featured in the exhibition present. Co-founder George Mallen and his wife Sarah Mallen were also able to be present, with the award for the furthest travelled going to long-time Computer Arts Society member Brian Reffin Smith, who came over especially for the exhibition opening from Berlin. The exhibition is well-documented on the Interact Digital Arts website (Interact Digital Arts 2019) and in the Computer Arts Society archive (2019).

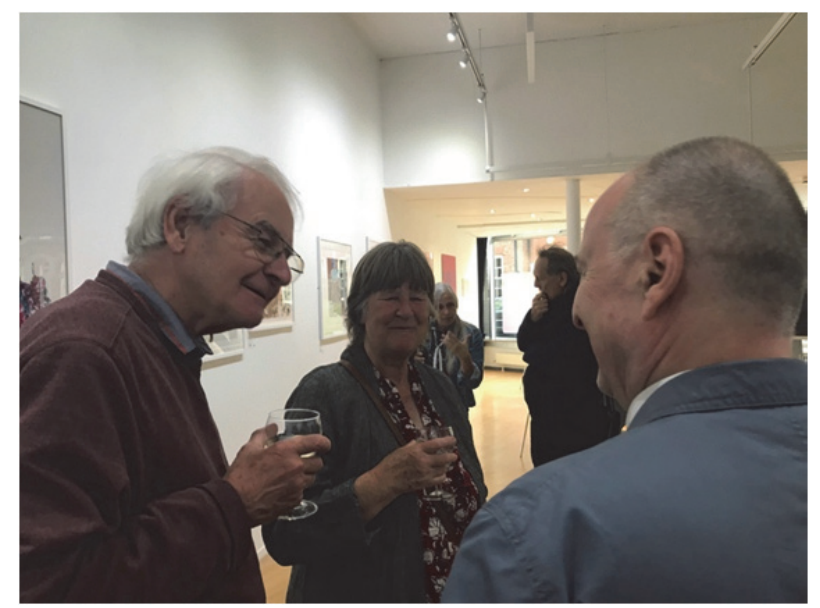

Figure 3: George Mallen (left), Sarah Mallen (centre) and Brian Reffin Smith (right) at the Leicester opening.

\subsection{The Brighton Exhibition}

After a presentation of the CAS50 Collection at EVA2018 in London in July 2018, the full exhibition was shown again at the Brighton Digital Festival between $13^{\text {th }}$ and $23^{\text {th }}$ September 2018.
The exhibition was hosted by Brighton Phoenix, an artist-led studio and exhibition space. The exhibition also coincided with a showcase of Lumen Prize 2018 shortlisted artworks. This resulted in a busy combined opening night.

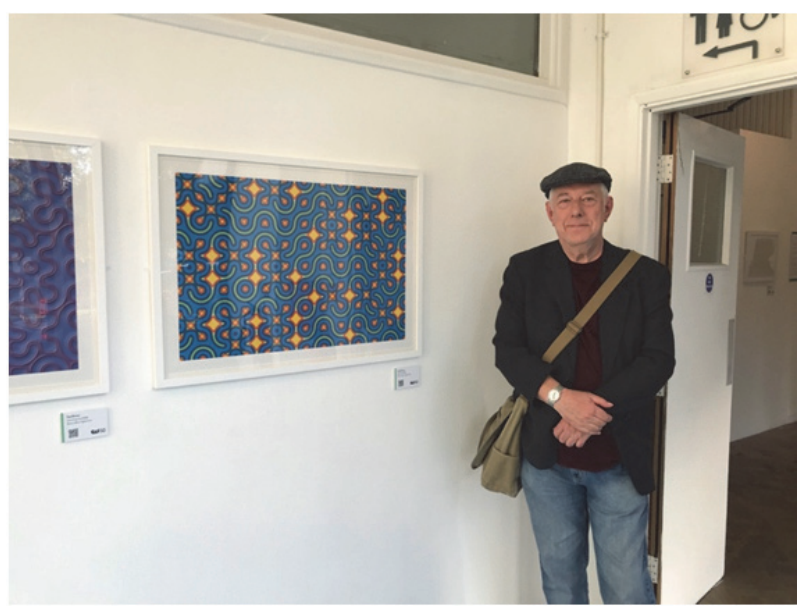

Figure 4: Paul Brown at the Brighton opening.

In addition to the twelve artists featured in the Leicester exhibition, very early computer artworks by Roger Saunders were also featured in Brighton. Roger was at Brighton Polytechnic in the late 1960s and early 1970s and was involved in the Computer Arts Society at the time.

Following the Brighton exhibition, a full colour exhibition catalogue was produced featuring information about the twelve artists, plus information about the Computer Arts Society and photographs of the exhibition opening events. This was made available as a limited edition print publication (Clark 2018) and is now available as a free PDF download (Interact Digital Arts 2019).

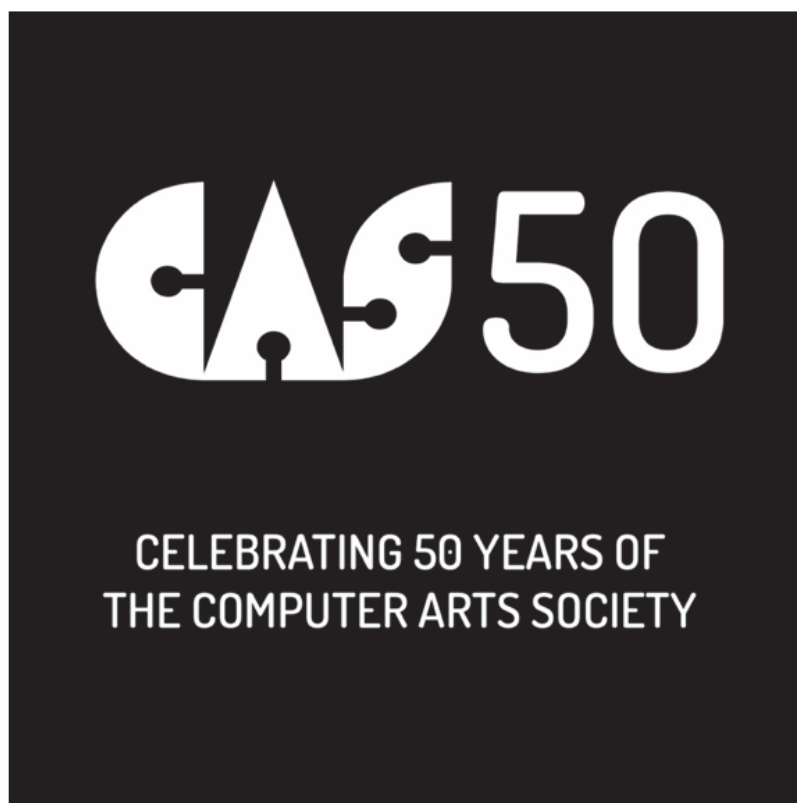

Figure 5: The CAS50 Exhibition catalogue. 


\section{THE CAS50 COLLECTION}

What started as an idea for a single celebratory exhibition has now become the basis of a collection of computer artworks produced by Computer Arts Society members and associates. The initial twelve artists are now being seen as "Phase 1" of the collection and a second phase is being put together of twelve more artists.

Phase 2 will be shown at the LCB Depot Lightbox Gallery in Leicester between $21^{\text {st }}$ July and $8^{\text {th }}$ August 2019. A selection of work from both phases will be included in the proposed Event Two exhibition at the Royal College of Art between $12^{\text {th }}$ and $19^{\text {th }}$ July 2019.

All of the work collected so far has been in the form of digital prints and images. This is in part due to the ease of collection and storage of prints. However, a "Phase 3" is being discussed that would focus on screen-based artworks.

Traditionally, the collection of digital artworks can be problematic due to the range of equipment and technologies used by artists. We plan to address this issue by creating a "reference platform" on which all collected digital artworks will need to run.

This platform, based around a single-board computer running an open operating system and using an LCD screen, will be fully specified shortly. Artworks will need to be adapted to run on the platform, but the hope is that it will allow video, algorithmic and generative artworks to be included in the collection with an eye to longevity of support.

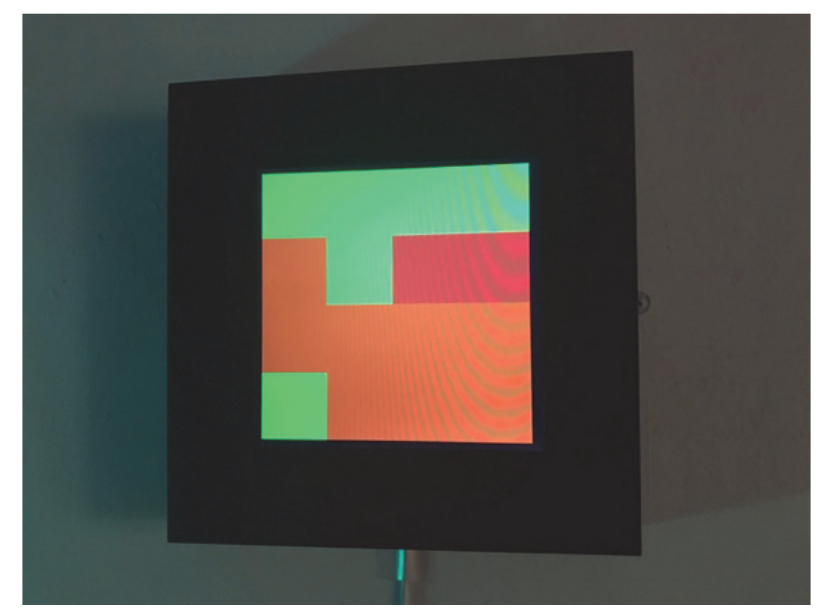

Figure 5: A Shaping Form image by Ernest Edmonds running on the CAS50 Collection reference platform.

At the In The Dark event at the Cello Factory in January 2019 (Genetic Moo 2019), versions of digital artworks by Ernest Edmonds, Paul Brown and Andy Lomas were run on an initial version of the platform.
As well as moving from prints in to screen-based work, the CAS50 Collection will also need attention in other areas. In particular the Phase 1 gender balance was not particularly even. This is being addressed somewhat in Phase 2, but may need more work in the future.

Finally, if the collection is to progress beyond two of three phases of curation then a permanent home for it will need to be found. This would ideally be at a university or public museum where it can be regularly shown and used for on-going research. If such a home can be found then I would like to think that at least some of the work might be featured in a future CAS100 exhibition.

For progress on the project visit: http://computerarts-society.com/cas50-collection

\section{ACKNOWLEDGEMENT}

This exhibition would not have been possible without the support of the BCS, Interact Digital Arts, Nicholas Lambert (Chair), Paul Brown (Treasurer) and Sean Clark (CAS50) of the Computer Arts Society and, of course, the participating artists. The introductory text of this paper was based on material taken from the Computer Arts Society website and may include contributions from multiple authors.

\section{REFERENCES}

Reichardt, J. (ed.) (1968) Cybernetic Serendipity. Studio International 1968, London, 1968.

Mason, C. A. (2008) Computer in the Art Room: The Origins of British Computer Arts 1950-1980. Quiller Press. ISBN 978-1899163892

Brown, P., Mason. C., Gere, C. and Lambert, N., (2009) White Heat Cold Logic: British Computer Art 1960-1980. MIT Press. ISBN 978-0262026536.

Clark, S. (2018) CAS50: Celebrating Fifty Years of the Computer Arts Society. Interact Digital Arts. ISBN 978-1-9993103-0-1

Computer Arts Society (2019) Archive.

http://computer-arts-society.com/archive (retrieved 25 March 2019).

Interact Digital Arts (2019) CAS50 Leicester. http://interactdigitalarts.uk/cas50 (retrieved 25 March 2019).

Genetic Moo (2019) In The Dark. http://www.geneticmoo.com/in-the-dark (retrieved 25 March 2019). 